\title{
Recovery during the weekend and fluctuations in weekly job performance: A week-level study examining intra-individual relationships
}

\author{
Carmen Binnewies ${ }^{1}$, Sabine Sonnentag ${ }^{2}$ and Eva J. Mojza ${ }^{2}$ \\ 'University of Mainz, Germany \\ ${ }^{2}$ University of Konstanz, Germany
}

\begin{abstract}
For most employees, the weekend offers the opportunity to recover and unwind from demands faced during the working week. In this study, first, we examined which factors contribute to employees' successful recovery during the weekend. Second, we investigated if being highly recovered after the weekend benefits different dimensions of job performance during the week. Using a within-person design we conducted a weeklevel study with 133 employees over four working weeks. Participants responded to weekly web-based surveys at the beginning and at the end of the working week. Hierarchical linear modelling showed that psychological detachment, relaxation, and mastery experiences during the weekend predicted the state of being recovered at the beginning of the working week. The state of being recovered in turn predicted fluctuations in weekly task performance, personal initiative, organizational citizenship behaviour, and low perceived effort. Our results stress the importance of recovery during the weekend for both the individual and for organizations.
\end{abstract}

Most employees would probably agree that at the end of a working week they look forward to the weekend. For many, the weekend offers the possibility to recover from work-related demands and to pursue pleasurable activities (Fritz \& Sonnentag, 2005), although some employees (e.g., nurses and salesclerks) have to work during the weekend. Research began to acknowledge the importance of vacations and daily recovery for employees' well-being, and performance (see for example, Eden, 2001; Sonnentag, 2003; Westman \& Eden, 1997). However, the role of weekends for employees' recovery and potential benefits for subsequent performance has been largely ignored (for an exception see Fritz \& Sonnentag, 2005).

In our study, we addressed this gap pursuing two general goals: first, we examined which factors contribute to an individual's recovery during the weekend. In particular, we proposed that specific recovery experiences (i.e., psychological detachment, relaxation, and mastery experiences) during the weekend foster an individual's state of

* Correspondence should be addressed to Dr Carmen Binnewies, Institute of Psychology, University of Mainz, Wallstrasse 3, D-55099 Mainz, Germany (e-mail: carmen.binnewies@uni-mainz.de). 
being recovered after the weekend. Second, we investigated if being highly recovered after the weekend (i.e., feeling physically and mentally refreshed) benefits job performance during the week. Specifically, we examined if an individual shows a higher level of task performance, proactive behaviour, organizational citizenship behaviour (OCB), and if the individual perceives accomplishing work less effortful in weeks when feeling highly recovered after the weekend.

We used a within-person design and assessed individual's recovery during the weekend and job performance over 4 weeks. Our study contributes to the literature in several ways. First, we add to the scarce literature on recovery during the weekend by using a within-person design over several weeks that has not been used in previous studies. Second, we enlarge our knowledge on the benefits of non-work experiences for individuals' behaviour at work (Demerouti, Taris, \& Bakker, 2007). Previous studies examining relations between recovery and performance investigated immediate effects within the same day (Sonnentag, 2003) or the first day after the weekend (Fritz \& Sonnentag, 2005). We explored if being recovered at the beginning of the working week benefits performance throughout the week. Third, our study contributes to the limited literature on dynamic performance (Beal, Weiss, Barros, \& MacDermid, 2005; Ilies, Scott, \& Judge, 2006; Trougakos, Beal, Green, \& Weiss, 2008) by examining the state of being recovered as a predictor of within-person fluctuations in performance over time.

\section{Recovery during the weekend and the state of being recovered after the weekend}

Accomplishing one's work and dealing with job demands requires individuals to invest physical and mental resources (Meijman \& Mulder, 1998). At the end of a working period (e.g., a day or a working week) an individual's resources are depleted and the individual is fatigued and experiences a need for recovery (Sluiter, van der Beek, \& Frings-Dresen, 1999). After work, and especially during the weekend, individuals have time to rest and unwind from job demands as they no longer have to deal with job demands and can 'recharge their batteries'. This process of unwinding and restoration is called recovery. Recovery is the process that reverses the negative consequences of job demands and allows an individual's functional system to return to the baseline level of functioning (Meijman \& Mulder, 1998).

According to the effort-recovery model (Meijman \& Mulder, 1998) recovery occurs when job demands no longer drain an individual's resources. If the individual is not confronted with job demands during the weekend, successful recovery should occur (Meijman \& Mulder, 1998). The conservation of resources (COR) model (Hobfoll, 1989) can further explain the recovery process. According to the COR framework (Hobfoll, 1989) individuals strive for gaining, preserving, and protecting resources. Resources are defined as 'those objects, personal characteristics, conditions, or energies that are valued by the individual or that serve as a means for attainment of these objects, personal characteristics, conditions, or energies' (Hobfoll, 1989, p. 516). During the weekend individuals have the opportunity to rebuild their resources and to gain additional resources, such as increased energy, positive affect, or self-efficacy (Fritz \& Sonnentag, 2005).

If successful recovery occurred during the weekend, the individual is more recovered after the weekend (usually on Monday). In this study, we focus on the state of being recovered after the weekend as an outcome of the recovery process. The state of being recovered indicates how much an individual feels physically and mentally refreshed (Sonnentag \& Kruel, 2006). 
Recovery experiences during the weekend and the state of being recovered after the weekend

Sonnentag and Fritz (2007) argued that it is probably not only a specific activity per se, but its underlying attributes that help individuals to recover. This means that individuals may pursue different activities, such as yoga or taking a bath while the underlying attribute contributing to recovery - in this case relaxation - may be the same across activities. Sonnentag and Fritz (2007) termed these underlying attributes recovery experiences. In our study, we focused on the recovery experiences psychological detachment, relaxation, and mastery experiences and examined if individuals are more recovered after weekends when having experienced a high level of these recovery experiences.

Etzion, Eden, and Lapidot (1998, p. 579) introduced the concept of psychological detachment and defined it as an 'individual's sense of being away from the work situation'. Psychological detachment not only involves being physically away from work, but also includes mentally switching off and not thinking about work-related issues or problems (Sonnentag \& Bayer, 2005). Drawing on the effort-recovery model (Meijman \& Mulder, 1998) and on COR model (Hobfoll, 1989), we propose that experiencing a higher level of psychological detachment during the weekend is related to a higher state of being recovered at the beginning of the working week. As psychological detachment means that the individual is both physically and mentally distanced from work (Etzion et al., 1998), his or her resources are no longer drained and can be restored (Hobfoll, 1989). When an individual experiences low psychological detachment during the weekend, he or she is still occupied with work resulting in further strain and poor recovery (Meijman \& Mulder, 1998).

Relaxation is a process that involves feeling calm and serene and is often associated with decreased physical activation as indicated, for example, by a decreased heart rate, breathing rate, or muscle tension (Smith, 2005). An individual may deliberately initiate relaxation by engaging in meditation (Grossman, Niemann, Schmidt, \& Walach, 2004), yoga (Sarang \& Telles, 2006), progressive muscle relaxation (Jacobsen, 1938), and similar techniques. Relaxation may also be experienced during other non-demanding activities, such as taking a bath or listening to music (Pelletier, 2004).

As relaxation is associated with a decrease in physical and psychological activation (Smith, 2005), it prevents a further resource loss resulting from prolonged activation due to work-related stress (Brosschot, Pieper, \& Thayer, 2005). Moreover, positive affect that comes along with relaxation (Stone, Kennedy-Moore, \& Neale, 1995) serves as a resource as positive emotions can undo the effects of negative emotions, and thereby help to prevent a further resource loss from experiencing negative emotions (Fredrickson, Mancuso, Branigan, \& Tugade, 2000). Thus, an individual should be more recovered after weekends when having experienced a high level of relaxation.

Mastery experiences during leisure time comprise off-job activities that are challenging for the individual and that provide an opportunity for learning and a sense of achievement (Sonnentag \& Fritz, 2007). Experiencing mastery involves feelings of competence and proficiency. An individual may experience mastery during leisure time when pursuing sport, learning a new hobby, or when engaging in volunteer activities (Ruderman, Ohlott, Panzer, \& King, 2002; Sonnentag \& Fritz, 2007).

Although engaging in activities that provide the opportunity to experience mastery requires some effort investment, mastery experiences should result in the restoration and acquisition of resources, such as new skills, increased self-efficacy, self-esteem, and positive affect (Parkinson \& Totterdell, 1999; Sonnentag \& Fritz, 2007). Therefore, after a weekend when having experienced a high level of mastery, an individual should have 
replenished and built up new resources and consequently feel highly recovered at the beginning of the working week.

With regard to empirical research, studies investigating between-person relations showed that persons who detach more and ruminate less about work-related issues have a better well-being (Brosschot, Gerin, \& Thayer, 2006; Sonnentag \& Fritz, 2007) as well as persons who experience more relaxation and mastery during leisure time and vacation (Fritz \& Sonnentag, 2006; Sonnentag \& Fritz, 2007). Moreover, daily survey studies investigating within-person relations found support for positive relations of detachment, relaxation, and mastery experiences during the evening with well-being at bedtime and in the next morning (Sonnentag \& Bayer, 2005; Sonnentag, Binnewies, \& Mojza, 2008). In sum, we propose:

Hypothesis I: Psychological detachment during the weekend will be positively related to the state of being recovered at the beginning of the working week.

Hypothesis 2: Relaxation during the weekend will be positively related to the state of being recovered at the beginning of the working week.

Hypothesis 3: Mastery experiences during the weekend will be positively related to the state of being recovered at the beginning of the working week.

The state of being recovered as predictor of fluctuations in weekly job performance The state of being recovered after the weekend is the outcome of the recovery process during the weekend representing an individual's level of restored psychological capital (Luthans, Avolio, Avey, \& Norman, 2007). As we investigated the state of being recovered as a predictor of within-person changes in performance, we based our propositions on a theoretical model of dynamic performance (Beal et al., 2005). According to Beal et al. (2005), dynamic performance mainly depends on whether the individual manages to allocate a maximum amount of resources to the task. Impaired resource allocation has the consequence that performance at this time will suffer (Beal et al., 2005). Successful resource allocation is mainly dependent on the amount of resources, especially self-regulatory resources, that are available for the individual (Beal et al., 2005). Therefore, Beal et al. (2005) conclude that the restoration and preservation of resources is critical for showing a high level of performance.

The state of being recovered at the beginning of the working week reflects the degree of recovery that occurred during the weekend implying that a high amount of resources is available for performing at work throughout the week. Similarly, being poorly recovered implies that resources for performing at work are sparse or even lacking.

In our study, we considered job performance as a multidimensional construct (Campbell, 1990) and included several performance outcomes. First, we focused on individuals' task performance, as it represents an individual's formally required contribution to organizational performance (Williams \& Anderson, 1991). Second, we considered two types of contextual performance, namely personal initiative (PI; Frese, Kring, Soose, \& Zempel, 1996) and the helping dimension of OCB (Smith, Organ, \& Near, 1983). PI represents a form of proactive behaviour (Crant, 2000) and is defined as 'a behaviour syndrome resulting in an individual taking an active and self-starting approach to work and going beyond what is formally required in a given job' (Frese et al., 1996, p. 38). Helping is a core dimension of OCB (Smith et al., 1983) and involves helping co-workers with tasks or problems (Podsakoff, MacKenzie, Paine, \& Bachrach, 
2000) as well as building and preserving interpersonal relations (Van Dyne \& LePine, 1998). As all performance behaviours require the investment of energy and resources, we hypothesize that weekly task performance as well as weekly PI and OCB will benefit from being highly recovered at the beginning of the week.

Regarding empirical evidence, results from a diary study of Sonnentag (2003) showed that day-level recovery (i.e., being recovered and relaxed in the morning) is positively related to daily PI. Another diary study of Binnewies, Sonnentag, and Mojza (2009) revealed that feeling highly recovered in the morning is related to increased task performance, PI, and OCB during the day. In addition, a study by Trougakos et al. (2008) showed that recovery during work breaks is positively related to subsequent performance of affective delivery. In sum, we propose:

Hypotheses 4-6: The state of being recovered at the beginning of the working week will be positively related to weekly task performance (Hypothesis 4), PI (Hypothesis 5), and OCB (Hypothesis 6)

In addition, we examined how straining and effortful it is for an individual to accomplish work during the week. Hockey (1993) argued that in order to prevent a decrease in performance, individuals will try to compensate for a suboptimal state (e.g., a low state of being recovered). They will spend more effort at work than usual and consequently perceive their work as more straining and effortful (Hockey, 1993). In weeks when an individual is poorly recovered at the beginning of the week, the individual possesses fewer resources, and therefore has to spend more effort to fulfil work tasks. In weeks when an individual is highly recovered at the beginning of the week, many resources are available and task accomplishment should be perceived as easier and less effortful. The diary study of Binnewies et al. (2009) showed that feeling highly recovered in the morning is associated with perceiving task accomplishment as less effortful during the day. Therefore, we state:

Hypothesis 7: The state of being recovered at the beginning of the working week will be negatively related to weekly perceived effort at work.

\section{Control variables}

To rule out alternative interpretations, we assessed a number of control variables. As all our measures are based on self-reports, we controlled for individuals' general level of negative affect to preclude that relations between recovery experiences and the state of being recovered or between the state of being recovered and weekly job performance are due to a person's general tendency to view his or her recovery and performance in a negative way (Podsakoff, MacKenzie, Jeong-Yeon, \& Podsakoff, 2003). Moreover, age may be related to both the state of being recovered and to weekly performance, and was therefore, included as a control variable. When predicting weekly performance, we additionally controlled for an individual's general level of task performance, PI, OCB, or perceived effort.

\section{Method}

Sample

We conducted our study in five German organizations including three manufacturing organizations from different industries, one service organization and one publisher. 
Each organization had about 500-1,000 employees. We only recruited employees working in areas such as administration and deliberately excluded blue-collar workers because (1) participants needed constant internet access for answering on-line surveys and (2) shiftwork arrangements typical for blue-collar jobs might interfere with recovery processes.

After establishing contact with an organization, we presented our study to different organizational committees in face-to-face meetings. As data were collected by an internet survey, organizations identified employees with regular internet access and sent them information about our study. To encourage participation we promised organization-specific feedback, announced a lottery prize, and offered participants to attend a training session on recovery that was conducted after data collection.

Participants had to fill in one general survey, four weekly surveys at the beginning of the working week (usually on Monday morning) and four weekly surveys at the end of the working week (usually on Friday afternoon) during four consecutive working weeks. Participants first received a link to the general internet survey. After coordinating a suitable 4-week time interval, participants received the link to fill in weekly internet surveys every week at the beginning and at the end of the working week. In cases where participants started the working week on Tuesday or finished the working week on Thursday, they received the link on the respective first or last day of the working week.

In sum, 193 employees registered to participate. This response rate is low compared to organizations' sizes but is quite common in a time-consuming longitudinal study (Baruch, 1999; Rogelberg \& Stanton, 2007). Due to missing data and because participants failed to fill in weekly surveys at the scheduled days, 60 persons were excluded from analyses. Our final sample consisted of 133 persons with weekly survey data from 406 weeks. Participants provided on average 3.1 weeks (range: 2-4 weeks) with complete data from both surveys.

About half of the participants were male (50.4\%). Participants' average age was 40.6 years $(S D=8.6)$, average job tenure was 17.4 years $(S D=11.6)$. Participants held a variety of jobs including managers (30.1\%), economists $(15.0 \%)$, commercial clerks (14.3\%), administrative staff (12.8\%), technicians (9.8\%), computer engineers $(9.0 \%)$, computer scientists (5.0\%), and journalists (5.7\%). Most participants worked full-time with an average working time of $40.6 \mathrm{~h}$ per week $(S D=10.0)$.

\section{Measures}

In the survey at the beginning of the working week, we measured participants' recovery experiences during the weekend as well as the momentary state of being recovered. In the survey at the end of the working week, we assessed weekly job performance and perceived effort. In the general survey, the general level of job performance, perceived effort, negative affect, and demographic data were assessed. All items were in German and had to be answered on five-point Likert scales (except for demographic data).

\section{Weekend recovery experiences}

Psychological detachment from work, mastery experiences, and relaxation during the weekend were measured retrospectively, each with four adapted items from the Recovery Experience Questionnaire (Sonnentag \& Fritz, 2007). Items were adapted to measure psychological detachment, relaxation, or mastery experiences experienced during the previous weekend (sample item for psychological detachment: 'During the 
weekend, I forgot about work'; sample item for relaxation: 'During the weekend, I did relaxing things'; sample item for mastery experiences: 'During the weekend, I did things that challenge me'). Cronbach's alpha ranged from .92 to $.95(M=0.94)$ for psychological detachment, from .82 to $.92(M=0.89)$ for relaxation, and from .82 to .90 $(M=0.85)$ for mastery experiences over the 4 weeks.

State of being recovered was measured by a four-item scale by Sonnentag and Kruel (2006). The scale refers to how recovered and well-rested a person feels. Items had to be answered with respect to how a person felt at the beginning of the working week. A sample item was 'I feel well rested'. Cronbach's alpha ranged from .88 to .92 $(M=0.91)$ over the 4 weeks.

Weekly task performance was measured with six items adapted from the performance scale of Roe, Zinovieva, Dienes, and Horn (2000). Our measure assessed how well an individual accomplished his or her work tasks during the last week. A sample item was 'This week, the results of my work could have been better than they were' (reverse coded). Cronbach's alpha ranged between .75 and $.84(M=0.80)$.

Weekly PI was assessed with an adapted seven-item scale of personal initiative (Frese, Fay, Hilburger, Leng, \& Tag, 1997) measuring the degree of PI shown at work during the week (sample item: 'This week, I actively attacked problems'). Cronbach's alpha ranged from .84 to $.91(M=0.88)$.

Weekly $O C B$ was assessed with three adapted items from the scale of Williams and Anderson (1991) measuring OCB directed at individuals. We included items that could be adapted to measure weekly OCB. Dropped items referred to OCB behaviours that are unlikely to occur every week (e.g., introducing new employees). The scale assessed how much a person helped and encouraged co-workers and ensured a pleasant working climate during the week (sample item: 'This week, I helped others who had heavy workloads'). Cronbach's alpha ranged between .68 and $.78(M=0.72)$.

Weekly perceived effort at work was measured with three items developed by Binnewies et al. (2009) and two additional items developed for this study. The scale measured how exhausting and straining it was to perform at work during the week (sample item: 'This week, it needed much energy to work on my tasks'). Cronbach's alpha ranged between .84 and $.91(M=0.88)$.

General level of negative affect was measured with six negative-affect items (sample items 'distressed', 'upset') from the Positive and Negative Affect Schedule (PANAS, Watson, Clark, \& Tellegen, 1988). Items were answered with respect to one felt 'in general'. Cronbach's alpha was .84 .

\section{General level of performance and perceived effort at work}

The general level of task performance, PI, OCB, and perceived effort at work was assessed with the same measures used in the weekly surveys. However, items had to be answered with respect to the general level of performance and perceived effort at work. Cronbach's alpha was .73 for task performance, .79 for PI, .64 for OCB and .83 for perceived effort at work.

We ran confirmatory factor analyses (CFAs) to confirm that variables measured in the survey at the beginning of the week (psychological detachment, mastery experiences, relaxation, and state of being recovered) represented distinct constructs. Because of the hierarchical structure of our data, we conducted CFAs with week-level data that was centred around the person mean as suggested by Bolger, Davis, and Rafaeli (2003). Results showed that the four-factor model showed a satisfactory fit $\left(\chi^{2}=360.32\right.$, 
$d f=98, p<.001$, root mean square error of approximation (RMSEA) $=.079$, comparative fit index $(\mathrm{CFI})=.95)$ and fit the data better than a one-factor model $\left(\Delta \chi^{2}=2371.82, d f=5, p<.001\right)$ and a two-factor model $\left(\Delta \chi^{2}=1577.00, d f=6\right.$, $p<.001$ ) where items from psychological detachment, relaxation, and mastery experiences during the weekend were specified to load on one factor. In addition, we conducted CFAs to confirm that our measures of task performance, PI, OCB, and perceived effort were best represented by four factors. Concerning weekly performance, CFAs were run with week-level performance data centred around the person mean. Results revealed that the four-factor model showed a satisfactory fit $\left(\chi^{2}=438.45, d f=183, p<.001, \mathrm{RMSEA}=.059, \mathrm{CFI}=.92\right)$ and fit the data better than a one-factor model $\left(\Delta \chi^{2}=1185.6, d f=6, p<.001\right)$, various three-factor $\left(\Delta \chi^{2} \geq 77.6\right.$, $d f=3, p<.001)$ and two-factor models $\left(\Delta \chi^{2} \geq 515.9, d f=5, p<.001\right)$. Regarding the general-level performance measures, CFAs results for the four-factor model also showed a satisfactory fit $\left(\chi^{2}=360.9, d f=183, p<.001\right.$, RMSEA $\left.=.080, \mathrm{CFI}=.90\right)$. This model also fit the data better than a one-factor model $\left(\Delta \chi^{2}=121.8, d f=6, p<.001\right)$, various three-factor $\left(\Delta \chi^{2} \geq 80.0, d f=3, p<.001\right)$ and two-factor models $\left(\Delta \chi^{2} \geq 222.8\right.$, $d f=5, p<.001)$.

\section{Data analyses}

We had data at two levels: the person level (Level 2) and the week level (Level 1). Weeklevel data were nested within persons. We used the MLwiN software (Rasbash et al., 2000) to analyse the data with hierarchical linear modelling (Snijders \& Bosker, 1999). To test for indirect effects of recovery experiences during the weekend on weekly performance, we applied multi-level structural equation modelling to our data (Mehta \& Neale, 2005) using the Mplus software (Muthén \& Muthén, 2006). To test our hypotheses, person-level predictor variables were centred around the grand mean while week-level predictor variables were centred around the respective person mean (group mean centring). We applied group mean centring because we were interested in withinperson relations.

\section{Results}

Means, $S D$ s, and zero-order correlations are displayed in Table 1. For calculating the correlations between week-level and person-level variables, week-level variables were averaged across the 4 weeks. Before testing hypotheses, we examined the variability of outcome variables across the 4 weeks. The null model (i.e., a model without any predictor variables) provides information about the distribution of variance components at both levels. ${ }^{1}$ For the outcome variable state of being recovered the variance at Level 1 was 0.369 , the variance at Level 2 was 0.329 (see Table 2), the total variance was 0.698 . Thus, $52.9 \%$ of the total variance was attributable to within-person variation and $47.1 \%$ was attributable to between-person variation. Regarding performance-related outcome variables the within-person variance was $43.3 \%$ for weekly task performance, $31.6 \%$ for weekly PI, $47.5 \%$ for weekly OCB, and $46.0 \%$ for weekly perceived effort (see Tables 3-6).

'These analyses were based on non-centred variables. 
Table I. Means, standard deviations, and zero-order correlations

\begin{tabular}{|c|c|c|c|c|c|c|c|c|c|c|c|c|c|c|c|}
\hline Variables & Mean & SD & 1 & 2 & 3 & 4 & 5 & 6 & 7 & 8 & 9 & 10 & 11 & 12 & 13 \\
\hline $\begin{array}{l}\text { (I) Detachment during the } \\
\text { weekend }\end{array}$ & 3.53 & 1.14 & & .25 & .15 & .30 & .07 & -.02 & -.12 & -.28 & & & & & \\
\hline $\begin{array}{l}\text { (2) Relaxation during the } \\
\text { weekend }\end{array}$ & 3.21 & 0.95 & .24 & & .27 & .38 & .03 & .08 & .01 & -.14 & & & & & \\
\hline $\begin{array}{l}\text { (3) Mastery experiences } \\
\text { during the weekend }\end{array}$ & 2.75 & 0.89 & .16 & .37 & & .27 & .08 & .14 & .17 & -.15 & & & & & \\
\hline $\begin{array}{l}\text { (4) State of being recovered at } \\
\text { the beginning of the week }\end{array}$ & 3.59 & 0.83 & .33 & .37 & .34 & & .19 & .27 & .03 & -.25 & & & & & \\
\hline (5) Weekly task performance & 4.01 & 0.58 & .08 & .03 & .06 & .20 & & .46 & .14 & -.31 & & & & & \\
\hline (6) Weekly PI & 3.58 & 0.72 & -.04 & .08 & .15 & .23 & .46 & & .33 & -.22 & & & & & \\
\hline (7) Weekly OCB & 2.61 & 0.95 & -.15 & .01 & .26 & -.04 & .15 & .39 & & -.07 & & & & & \\
\hline (8) Weekly perceived effort & 2.67 & 0.88 & -.33 & -.16 & -.24 & -.25 & -.30 & -.20 & -.09 & & & & & & \\
\hline $\begin{array}{l}\text { (9) General level of task } \\
\text { performance }\end{array}$ & 3.98 & 0.48 & .19 & .04 & .07 & .12 & .43 & .22 & .19 & -.16 & & & & & \\
\hline (10) General level of PI & 3.68 & 0.49 & -.07 & .16 & .24 & .12 & .32 & .52 & .30 & -.05 & .40 & & & & \\
\hline (II) General level of OCB & 3.78 & 0.56 & .19 & .14 & .13 & .13 & .19 & .17 & .45 & -.24 & .17 & .11 & & & \\
\hline $\begin{array}{l}\text { (12) General level of } \\
\text { perceived effort }\end{array}$ & 2.56 & 0.74 & -.35 & -.24 & -.06 & -.24 & -.16 & -.08 & -.06 & .59 & -.32 & -.16 & -.32 & & \\
\hline $\begin{array}{l}\text { (13) General level of } \\
\text { negative affect }\end{array}$ & 1.71 & 0.61 & -.34 & -.10 & -.06 & -.30 & -.27 & .01 & .09 & .27 & -.22 & -.12 & -.02 & .30 & \\
\hline (14) Age & 40.64 & 8.68 & -.08 & -.18 & -.09 & -.01 & .03 & -.08 & -.27 & .04 & -.07 & -.02 & -.05 & .25 & .07 \\
\hline
\end{tabular}

Note. Correlations below the diagonal are person-level correlations $(N=133)$ with correlations $r \geq|.18|$ being significant at $p<.05$ and $r \geq|.23|$ being significant at $p<.01$. Correlations above the diagonal are week-level correlations $(N=406)$ with correlations $r \geq|.10|$ being significant at $p<.05$ and $r \geq|.13|$ being significant at $p<.01$ 
Table 2. Multilevel estimates for models predicting state of being recovered at the beginning of the week

\begin{tabular}{|c|c|c|c|c|c|c|c|c|c|}
\hline & \multicolumn{3}{|c|}{ Null model } & \multicolumn{3}{|c|}{ Model I } & \multicolumn{3}{|c|}{ Model 2} \\
\hline & Estimate & SE & $t$ & Estimate & SE & $t$ & Estimate & SE & $t$ \\
\hline Intercept & 3.581 & 0.059 & 60.695 & 3.582 & 0.056 & 63.964 & 3.585 & 0.055 & 65.182 \\
\hline General level of negative affect & & & & -0.335 & 0.092 & -3.641 *16k & -0.337 & 0.091 & $-3.703^{* 010 \mathrm{k}}$ \\
\hline Age & & & & 0.001 & 0.006 & 0.167 & 0.001 & 0.006 & 0.167 \\
\hline Detachment during the weekend & & & & & & & 0.164 & 0.050 & $3.280 \%$ \\
\hline Relaxation during the weekend & & & & & & & 0.238 & 0.049 & $4.878^{\% \ldots \%}$ \\
\hline Mastery experiences during the weekend & & & & & & & 0.101 & 0.050 & 2.020 \\
\hline$-2 \log (l h)$ & & & 919.270 & & & 906.584 & & & 855.273 \\
\hline Diff $-2 \log$ & & & & & & $12.584^{* * * *}$ & & & $51.311 \% * *$ \\
\hline Diff $d f$ & & & & & & 2 & & & 3 \\
\hline Level I intercept variance $(S E)$ & & $.369(0.032)$ & & & $0.369(0.032)$ & & & $0.308(0.026)$ & \\
\hline Level 2 intercept variance (SE) & & $.329(0.057)$ & & & $0.287(0.052)$ & & & $0.302(0.05 \mathrm{I})$ & \\
\hline
\end{tabular}

Note. $\mathrm{N}$ on person-level $=133, \mathrm{~N}$ on week-level $=406 . * p<.05 ; * p<.01 ; * * * p<.001$. 
Table 3. Multilevel estimates for models predicting weekly task performance

\begin{tabular}{|c|c|c|c|c|c|c|c|c|c|}
\hline & \multicolumn{3}{|c|}{ Null model } & \multicolumn{3}{|c|}{ Model I } & \multicolumn{3}{|c|}{ Model 2} \\
\hline & Estimate & SE & $t$ & Estimate & SE & $t$ & Estimate & SE & $t$ \\
\hline Intercept & 4.007 & 0.042 & 95.405 & 4.007 & 0.037 & 108.297 & 4.006 & 0.037 & 108.270 \\
\hline General level of negative affect & & & & -0.143 & 0.062 & $-2.306 *$ & -0.142 & 0.062 & $-2.290 *$ \\
\hline Age & & & & 0.004 & 0.004 & 1.000 & 0.004 & 0.004 & 1.000 \\
\hline General level of task performance & & & & 0.421 & 0.079 & $5.329 * * * *$ & 0.422 & 0.079 & 5.342 \%क\% \\
\hline State of being recovered at the beginning of the week & & & & & & & 0.074 & 0.037 & $2.000 *$ \\
\hline$-2 \log (/ h)$ & & & 573.114 & & & 537.461 & & & 533.491 \\
\hline Diff $-2 \log$ & & & & & & $35.653 * \%$ & & & $3.970 *$ \\
\hline Diff $d f$ & & & & \multirow{2}{*}{\multicolumn{3}{|c|}{$0.144(0.012)^{3}$}} & \multirow{2}{*}{\multicolumn{3}{|c|}{$0.142(0.012)$}} \\
\hline Level I intercept variance (SE) & \multicolumn{3}{|c|}{$0.143(0.012)$} & & & & & & \\
\hline Level 2 intercept variance (SE) & \multicolumn{3}{|c|}{$0.187(0.029)$} & \multicolumn{3}{|c|}{$0.129(0.022)$} & \multicolumn{3}{|c|}{$0.129(0.022)$} \\
\hline
\end{tabular}

Note. $\mathrm{N}$ on person-level $=133 . \mathrm{N}$ on week-level $=406$. *p $<.05$; *kp $<.01 ; *$ *kp $<.001$. 
Table 4. Multilevel estimates for models predicting weekly PI

\begin{tabular}{|c|c|c|c|c|c|c|c|c|c|}
\hline & \multicolumn{3}{|c|}{ Null model } & \multicolumn{3}{|c|}{ Model I } & \multicolumn{3}{|c|}{ Model 2} \\
\hline & Estimate & SE & $t$ & Estimate & SE & $t$ & Estimate & SE & $t$ \\
\hline Intercept & 3.574 & 0.055 & 64.982 & 3.574 & 0.047 & 76.043 & 3.573 & 0.046 & 77.674 \\
\hline General level of negative affect & & & & 0.075 & 0.077 & 0.974 & 0.078 & 0.077 & 1.013 \\
\hline Age & & & & -0.005 & 0.005 & -1.000 & -0.005 & 0.005 & -1.000 \\
\hline General level of PI & & & & 0.695 & 0.096 & $7.240^{* * 2 \%}$ & 0.694 & 0.095 & $7.305^{* * * *}$ \\
\hline $\begin{array}{l}\text { State of being recovered at the } \\
\text { beginning of the week }\end{array}$ & & & & & & & 0.149 & 0.039 & 3.821 *ack \\
\hline$-2 \log (I h)$ & & & 678.714 & & & 633.739 & & & 619.414 \\
\hline Diff $-2 \log$ & & & & & & $44.975^{* * * *}$ & & & $14.325 * \%$ \\
\hline Diff $d f$ & & & & & & 3 & & & 1 \\
\hline Level I intercept variance (SE) & & $0.162(0.014)$ & & & $0.162(0.01$ & & & $0.154(0.013)$ & \\
\hline Level 2 intercept variance $(S E)$ & & $0.351(0.050)$ & & & $0.233(0.03$ & & & $0.234(0.035)$ & \\
\hline
\end{tabular}

Note. $\mathrm{N}$ on person-level $=133, \mathrm{~N}$ on week-level $=406 . * p<.05 ; * \neq<<.01 ; * * * p<.001$. 
Table 5. Multilevel estimates for models predicting weekly OCB

\begin{tabular}{|c|c|c|c|c|c|c|c|c|c|}
\hline & \multicolumn{3}{|c|}{ Null model } & \multicolumn{3}{|c|}{ Model I } & \multicolumn{3}{|c|}{ Model 2} \\
\hline & Estimate & SE & $t$ & Estimate & SE & $t$ & Estimate & SE & $t$ \\
\hline Intercept & 2.602 & 0.068 & 38.265 & 2.603 & 0.058 & 44.879 & 2.602 & 0.058 & 44.862 \\
\hline General level of negative affect & & & & 0.165 & 0.095 & 1.737 & 0.167 & 0.095 & 1.758 \\
\hline Age & & & & -0.023 & 0.007 & $-3.286 * *$ & -0.023 & 0.007 & -3.286 ** \\
\hline General level of OCB & & & & 0.628 & 0.102 & $6.157 * * *$ & 0.626 & 0.102 & $6.137^{* * * 1}$ \\
\hline $\begin{array}{l}\text { State of being recovered at the } \\
\text { beginning of the week }\end{array}$ & & & & & & & 0.119 & 0.060 & $1.983^{*}$ \\
\hline$-2 \log (I h)$ & & & 1000.603 & & & 955.952 & & & 952.029 \\
\hline Diff $-2 \log$ & & & & & & 44.651 \% & & & $3.923 *$ \\
\hline Diff $d f$ & & & & & & 3 & & & 1 \\
\hline Level I intercept variance (SE) & & $0.428(0.037)$ & & & $0.429(0.037)$ & & & $0.423(0.036)$ & \\
\hline Level 2 intercept variance (SE) & & $0.472(0.077)$ & & & $0.293(0.055)$ & & & $0.296(0.055)$ & \\
\hline
\end{tabular}

Note. $\mathrm{N}$ on person-level $=133 . \mathrm{N}$ on week-level $=406 . * p<.05 ; * \mathrm{*ak}<.01 ; * \mathrm{k} p<.001$. 
Table 6. Multilevel estimates for models predicting weekly perceived effort

\begin{tabular}{|c|c|c|c|c|c|c|c|c|c|}
\hline & \multicolumn{3}{|c|}{ Null model } & \multicolumn{3}{|c|}{ Model I } & \multicolumn{3}{|c|}{ Model 2} \\
\hline & Estimate & $S E$ & $t$ & Estimate & SE & $t$ & Estimate & SE & $t$ \\
\hline Intercept & 2.659 & 0.063 & 42.206 & 2.666 & 0.050 & 53.320 & 2.666 & 0.050 & 53.320 \\
\hline General level of negative affect & & & & 0.128 & 0.085 & 1.506 & 0.128 & 0.085 & 1.506 \\
\hline Age & & & & -0.010 & 0.006 & -1.667 & -0.010 & 0.006 & -1.667 \\
\hline General level of perceived effort & & & & 0.585 & 0.072 & $8.125 \%$ & 0.580 & 0.073 & $7.945 \%$ \\
\hline State of being recovered at the & & & & & & & -0.133 & 0.058 & $-2.293^{*}$ \\
\hline \multicolumn{10}{|l|}{ beginning of the week } \\
\hline$-2 \log (I h)$ & & & 924.505 & & & 861.789 & & & 856.554 \\
\hline Diff $-2 \log$ & & & & & & $62.716^{* * 1 * *}$ & & & $5.235^{*}$ \\
\hline Diff $d f$ & & & & & & 3 & & & 1 \\
\hline Level I intercept variance (SE) & & $0.349(0.030)$ & & & $0.351(0.030)$ & & & $0.344(0.029)$ & \\
\hline Level 2 intercept variance (SE) & & $0.409(0.066)$ & & & $0.206(0.041)$ & & & $0.210(0.04 I)$ & \\
\hline
\end{tabular}

Note. $\mathrm{N}$ on person-level $=133, \mathrm{~N}$ on week-level $=406$. $* p<.05 ;$ **kp $<.01 ;$ **⿲二丨匕 $<.001$. 
To test for the relations between recovery experiences and the state of being recovered (Hypotheses 1-3) and for the relations between the state of being recovered and weekly job performance (Hypotheses 4-7) we conducted multi-level analyses for each outcome variable (i.e., for the state of being recovered, weekly task performance, weekly PI, weekly OCB, and weekly perceived effort at work). We specified and compared different models for each outcome variable: null model, Model 1 and Model 2, Model 3. In the null model, the intercept was the only predictor. In Model 1, control variables at the person level (e.g., general level of negative affect, age) were entered. In Model 2, we entered week-level predictors (e.g., recovery experiences during the weekend or the state of being recovered) to test our hypotheses.

Table 2 displays the results for the state of being recovered as an outcome variable. Model 1 showed that the general level of negative affect negatively predicted the state of being recovered. In Model 2 all predictor variables, i.e., psychological detachment, mastery experiences, and relaxation appeared as positive predictors of the state of being recovered. After weekends when an individual experienced high levels of detachment, mastery, and relaxation, the individual felt more recovered at the beginning of the week. Consequently, Hypotheses 1-3 were supported.

Tables 3-6 show the results for weekly task performance, PI, OCB, and perceived effort at work. With regard to person-level control variables (see Model 1), the general level of the outcome variable predicted performance and perceived effort at work during the week for all outcomes. The general level of negative affect was a negative predictor of weekly task performance, but unrelated to weekly PI, OCB, and perceived effort. Age negatively predicted weekly OCB. As hypothesized the state of being recovered (see Model 2) positively predicted weekly task performance, PI, and OCB and negatively predicted weekly perceived effort at work. In weeks when an individual indicated a higher state of being recovered at the beginning of the week the individual showed a higher level of weekly task performance, PI, and OCB and perceived work as less effortful. Therefore, Hypotheses 4-7 were confirmed.

Testing for indirect effects of recovery experiences on weekly job performance As we found that recovery experiences during the weekend predicted the state of being recovered at the beginning of the working week and the state of being recovered predicted weekly job performance, one may ask if the state of being recovered at the beginning of the week is the linking mechanism. Therefore, we tested for indirect effects of recovery experiences on weekly job performance (Mathieu \& Taylor, 2006). An indirect effect between predictor and criterion is indicated if predictor and outcome are not directly related, ${ }^{2}$ but if a predictor is related to a 'mediator' that in turn links the predictor to the outcome (Mathieu \& Taylor, 2006).

To test for indirect effects we specified a multi-level structural equation model (SEM) using the software Mplus (Muthén \& Muthén, 2006). Multilevel SEM combines structural equation modelling with the analysis of hierarchical data (Kaplan \& Elliott, 1997; Mehta \& Neale, 2005; Muthén \& Satorra, 1995). For both predictor and outcome variables variance components at Levels 1 and 2 are determined and modelled and path

\footnotetext{
${ }^{2}$ Additional multilevel analyses showed recovery experiences to be unrelated with weekly performance. Therefore, we did not find a direct effect that would be a precondition for mediation analyses. Tables with results are available from Carmen Binnewies on request.
} 
analyses can be used to test predicted relations at both levels (Kaplan \& Elliott, 1997; Mehta \& Neale, 2005).

We specified a simplified model only containing predictor, linking, and outcome variables (see our model in Figure 1). We did not integrate the measurement model in order to have sufficient cases for the number of parameters to be estimated on both levels (Mehta \& Neale, 2005). Analogous to multi-level analyses predictor variables were centred around the respective person mean. As the between-person variance was thereby removed, these variables were only modelled at Level 1 . We did not centre the state of being recovered and weekly performance as they were outcome variables. The between-person variance components of the state of being recovered and weekly performance variables were modelled as latent factors at Level 2. Regarding the path model at Level 1, we specified paths from psychological detachment, mastery experiences, and relaxation to the state of being recovered and from the state of being recovered to weekly task performance, PI, OCB, and perceived effort. At Level 2, we also specified the paths from the state of being recovered to weekly task performance, PI, OCB, and perceived effort assuming that individuals who are more recovered than others show higher task performance, PI, OCB, and perceive their work as less effortful. Covariances between predictors and performance variables were included as results from correlation analyses and CFAs showed that predictor and outcome variables, respectively represent distinct but highly related constructs.

Figure 1 displays standardized estimates of path coefficients. In sum, our model showed a very good fit to the data $\left(\chi^{2}=14.1, d f=12, p=.30\right)$ and the calculation of

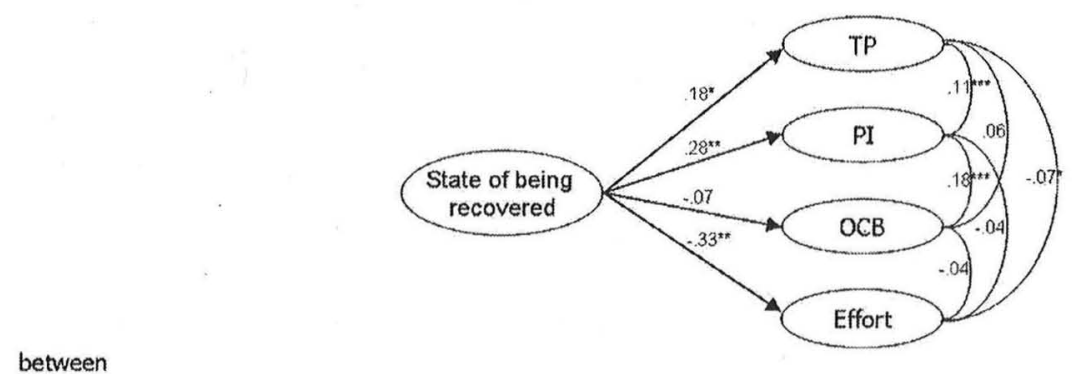

within

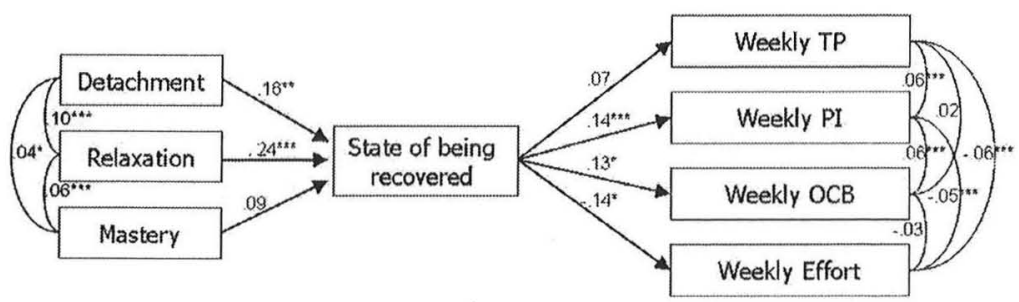

Figure I. Results for multilevel structural equation model, modelling relations between recovery experiences, state of being recovered, and job performance.

Note. $x^{2}=14.074, d f=12, p=.30$, RMSEA $=.021, C F I=.992$, Tucker-Lewis Index $(T L I)=.976$; $* p<.05 ; * * p<.01 ; * * * p<.00 \mathrm{I} ; \mathrm{TP}$, task performance; PI, personal initiative; OCB, organisational citizenship behaviour. 
the RMSEA (.021) and the CFI (.992) indicated an excellent fit. Estimated path coefficients were significant as were regression coefficients in multi-level analyses, with the exception that mastery experiences during the weekend were no longer significantly related to the state of being recovered and the state of being recovered was no longer significantly related to weekly task performance.

For testing the indirect effects we calculated the indirect effects for each predictor and outcome variable using the procedure of Baron and Kenny (1986). Table 7 shows the results for all indirect effects. We found indirect effects of psychological detachment on weekly PI, and of relaxation on weekly PI and perceived effort at work.

\section{Discussion}

The aim of our study was to examine recovery experiences during the weekend as predictors of being recovered after the weekend and to investigate if the state of being recovered after the weekend benefits weekly job performance. Results from multi-levelanalyses showed that psychological detachment, relaxation, and mastery experiences during the weekend were positively related to the state of being recovered at the beginning of the working week. The state of being recovered in turn was positively related to weekly task performance, PI, and OCB and negatively related to perceived effort at work. Analysing our data with a multi-level SEM approach revealed indirect effects of psychological detachment and relaxation on weekly PI and an indirect effect of relaxation on perceived effort at work.

Taken together, our results support the view that prevention of continued resource drain and restoration of resources by mentally switching off from work, reducing a state of prolonged activation and by pursuing challenging activities contribute to an increased level of resources and thus to a higher state of being recovered. Our study complemented results from other studies using different designs and investigating different time-intervals that showed beneficial effects of recovery experiences for employees' affect and well-being (Sonnentag et al., 2008). However, the relation between mastery experiences and the state of being recovered was small and not supported in the multi-level SEM model. We think that this inconsistency results from simultaneously testing for all effects which is a more conservative approach than testing separate effects in multi-level analyses. The positive effect of mastery may be small as investment of effort and self-regulatory resources typical for mastery processes may decrease the positive effect of mastery experiences in the short-run.

Considering the link between the state of being recovered and weekly performance, our results suggest that in weeks when individuals are highly recovered, they have more resources available that can be allocated to work tasks and thus benefit weekly performance. We found the strongest relation with weekly PI. As PI is a self-initiated behaviour, increasing PI may be easier than increasing task performance or OCB. Increasing task performance and OCB may be more difficult because these behaviours may be more contingent on situational factors (Stewart \& Nandkeolyar, 2006). Whether a highly recovered individual actually increases weekly $O C B$ probably largely depends on co-workers needing help. Similarly, the accomplishment of many tasks may be standardized limiting an individual's possibilities to increase the quality of task performance and individuals probably counteract a decrease in task performance as this may also be associated with negative consequences. 
Table 7. Results for testing indirect mediation effects of recovery experiences on weekly job performance

\begin{tabular}{|c|c|c|c|c|c|c|c|c|}
\hline Predictor variable & Outcome variable & Path $a$ & SE & Path $b$ & SE & Indirect effect $a \times b$ & SE & $\mathrm{z}$ \\
\hline \multirow[t]{4}{*}{ Detachment } & Weekly task performance & 0.161 & 0.056 & 0.068 & 0.038 & 0.011 & 0.008 & 1.46 \\
\hline & Weekly PI & 0.161 & 0.056 & 0.142 & 0.040 & 0.023 & 0.010 & $2.18 *$ \\
\hline & Weekly OCB & 0.161 & 0.056 & 0.131 & 0.066 & 0.021 & 0.013 & 1.57 \\
\hline & Weekly perceived effort & 0.161 & 0.056 & -0.141 & 0.059 & -0.023 & 0.013 & -1.78 \\
\hline \multirow[t]{4}{*}{ Relaxation } & Weekly task performance & 0.239 & 0.055 & 0.068 & 0.038 & 0.016 & 0.010 & 1.62 \\
\hline & Weekly PI & 0.239 & 0.055 & 0.142 & 0.040 & 0.034 & 0.013 & $2.71^{* *}$ \\
\hline & Weekly OCB & 0.239 & 0.055 & 0.137 & 0.066 & 0.031 & 0.018 & 1.77 \\
\hline & Weekly perceived effort & 0.239 & 0.055 & -0.141 & 0.059 & -0.034 & 0.016 & $-2.05^{*}$ \\
\hline \multirow[t]{4}{*}{ Mastery experiences } & Weekly task performance & 0.093 & 0.058 & 0.068 & 0.038 & 0.006 & 0.006 & 1.10 \\
\hline & Weekly PI & 0.093 & 0.058 & 0.142 & 0.040 & 0.013 & 0.009 & 1.42 \\
\hline & Weekly OCB & 0.093 & 0.058 & 0.137 & 0.066 & 0.012 & 0.010 & 1.16 \\
\hline & Weekly perceived effort & 0.093 & 0.058 & $-0.14 I$ & 0.059 & -0.013 & 0.010 & -1.26 \\
\hline
\end{tabular}

Note. $\mathrm{N}$ on person-level $=133, \mathrm{~N}$ on week-level $=406 . * p<.05 ; *$ * $<$ < $01 ; * * * \mathrm{p}<.001$. 
As expected, an individual perceived the accomplishment of his or her tasks as less effortful and straining in weeks when he or she was highly recovered. Thus, the state of being recovered not only benefits weekly job performance but also decreases the psychological costs of accomplishing tasks during the week. This finding supports the view that a high state of being recovered is associated with an increased level of resources that facilitates resource allocation to job tasks and makes task accomplishment easier (Beal et al., 2005). Reducing the psychological costs of task accomplishment seems to be particularly important for showing high performance over a longer period of time and for preventing negative long-term effects of a sustained high-effort investment, such as chronic fatigue.

Beyond results on the hypothesized within-person relations, multi-level SEM analyses provided information on the relation between the state of being recovered and weekly job performance on the between-person level. Although, we cannot rule out the potential influence of third variables on relations at the person level, the relation between the state of being recovered and weekly job performance seems to hold both within and between persons for weekly PI and perceived effort, whereas a relation between feeling recovered and weekly OCB was just found at the within-person level.

\section{Limitations}

This study has several limitations. First, our performance measures were assessed by selfreports that are subject to social desirability and self-serving bias. However, the design of our study and procedure of data analyses (e.g., centring predictor variables around the respective person mean) should rule out interpretations based on differences between individuals. Such between-person differences and biases should be related to the absolute level of performance and not to weekly fluctuations in performance. Of course, future studies have to examine if the relations are also found when using objective data and supervisor or peer ratings as performance indicators. However, investigating the dynamic nature of performance over short periods of time, researchers have to choose indicators that are able to reflect short-term changes in performance. Although supervisors may be good in evaluating employees' general level of performance, they might be less capable in evaluating employees' change in performance from week to week.

Second, common method variance might be a problem (Podsakoff et al., 2003). We tried to minimize this problem by temporally separating the predictor and outcome measures whenever possible. Specifically, we assessed person-level control variables in the general survey, recovery experiences and the state of being recovered in the weekly survey at the beginning of the week, and weekly job performance in the weekly survey at the end of the working week. This procedure should have reduced common method variance (Podsakoff et al., 2003). Moreover, by controlling for a person's general level of negative affect we ruled out alternative explanations such as that our results are simply due to a negative perceptual bias. Nevertheless, future studies should aim at assessing other source data, for example by asking spouses about their partner's recovery experiences.

In the weekly survey at the beginning of the week, participants retrospectively assessed recovery experiences during the weekend. It might be that these ratings are largely influenced by the last day of the weekend. In some cases (e.g., because of a holiday) surveys were filled out on Tuesday and not on Monday what might have changed participants ratings of recovery experiences during the weekend. Therefore, 
future research should clarify these questions by assessing recovery experiences throughout the weekend and comparing relations with retrospective ratings.

The response rate in our study was quite low considering organizations' sizes. Although this is not unusual in time-consuming longitudinal studies (Baruch, 1999; Rogelberg \& Stanton, 2007) it may limit the generalization of our results. For example, employees with a high level of stress may be underrepresented as research showed that these employees are less likely to participate in organizational surveys (Barr, Spitzmüller, \& Stuebing, 2008).

In addition, we cannot draw conclusions about causal relations between our variables. Experimental studies or intervention studies manipulating recovery experiences are needed to confirm the causal links of proposed relations.

\section{Implications for research and practice}

Now that we established a link between recovery experiences during the weekend with the state of being recovered after the weekend and between the state of being recovered and weekly job performance, future studies should investigate which resources are restored and built up during the recovery process and which resources are the mediating mechanisms in the relation between recovery and performance. Selfregulatory resources or energy representing the capability to perform and the willingness to invest resources representing the motivation to perform may be examined as mediators.

As our study focused on recovery during the weekend and weekly job performance, future research should examine the interplay with recovery during the week. Is recovery during the week less important if an individual is highly recovered after the weekend? Can recovery during the week compensate for a poor recovery during the weekend? Future studies may examine how the effects of being recovered after the weekend fade out during the week. Workplace characteristics, such as stressors or resources that consume or replenish individuals' resources may accelerate or decelerate such a fade-out process.

In addition, future research should examine cumulative effects of recovery over time and over longer time intervals than weeks. For example, what happens if an individual lacks recovery over weeks or even months? This is particularly important because some recovery processes, such as psychological detachment may be effective in the short-run and other processes, such as mastery experiences may unfold their effects in the long-run.

Results from our study also have practical implications. Assuming that recovery experiences during the weekend cause the state of being recovered after the weekend and that being recovered in turn causes an increase in weekly job performance and a decrease in perceived effort, our study implies that employees should be supported to recover during the weekend. Improving psychological detachment, relaxation, and mastery experiences during the weekend by providing specific interventions or recommendations should benefit a persons' state of being recovered. Organizations and employees should be aware that being recovered after the weekend is not only a pleasant experience but is also critical for weekly job performance and performancerelated costs. Therefore, organizations should support and enable employees' recovery during the weekend as it benefits both the employee and the organization. However, organizational interferences into employees' private lives may also be problematic and even counterproductive. Therefore, organizational efforts should aim at supporting 
employees in finding and realizing their own way to successful recovery during leisure time.

Moreover, our study revealed that weekly proactive behaviour can be indirectly supported by fostering psychological detachment and relaxation during the weekend. In addition, relaxation indirectly contributes to employees' weekly OCB and decreases the psychological costs of performance.

\section{Acknowledgements}

This study is part of Carmen Binnewies' dissertation and was funded by a grant from the German Research Community (DFG; SO 295/4-1, 4-2) that is gratefully acknowledged. We would like to thank Franziska Bertram, Claudius Bornemann, Stefanie Ernst, Verena Hahn, Till Kastendieck, Nadja Metzler, Frithjof Müller, Christian Peters, Sonja Riefer, Annika Scholl, Julia Schweda, and Ines Spitzner for their support during data collection and Katherine N. Alexander, Charlotte Fritz, Anne Spychala as well as Jonathon R. B. Halbesleben and anonymous reviewers for helpful comments on earlier versions of this paper.

\section{References}

Baron, R. M., \& Kenny, D. A. (1986). The moderator-mediator variable distinction in social psychological research: Conceptual, strategic, and statistical considerations. Journal of Personality and Social Psychology, 51, 1173-1182.

Barr, C. D., Spitzmüller, C., \& Stuebing, K. K. (2008). Too stressed out to participate? Examining the relation between stressors and survey response behavior.Journal of Occupational Health Psychology, 13, 232-243.

Baruch, Y. (1999). Response rate in academic studies - A comparative analysis. Human Relations, $52,421-438$.

Beal, D. J., Weiss, H. M., Barros, E., \& MacDermid, S. M. (2005). An episodic process model of affective influences on performance. Journal of Applied Psychology, 90, 1054-1068.

Binnewies, C., Sonnentag, S., \& Mojza, E. J. (2009). Daily performance at work: Feeling recovered in the morning as a predictor of day-level job performance. Journal of Organizational Behavior, 30, 67-93.

Bolger, N., Davis, A., \& Rafaeli, E. (2003). Diary methods: Capturing life as it is lived. Annual Review of Psychology, 54, 579-616.

Brosschot, J. F, Gerin, W., \& Thayer, J. F. (2006). The perseverative cognition hypothesis: A review of worry, prolonged stress-related physiological activation, and health. Journal of Psychosomatic Research, 60, 113-124.

Brosschot, J., Pieper, S., \& Thayer, J. (2005). Expanding stress theory: Prolonged activation and perseverative cognition. Psychoneuroendocrinology, 30, 1043-1049.

Campbell, J. P. (1990). Modeling the performance prediction problem in industrial and organizational psychology. In M. D. Dunnette \& L. M. Hough (Eds.), Handbook of industrial and organizational psychology (2nd ed., Vol. 1, pp.687-732). Palo Alto, CA: Consulting Psychologists Press, Inc.

Crant, J. M. (2000). Proactive behavior in organizations. Journal of Management, 26, 435-462.

Demerouti, E., Taris, T. W., \& Bakker, A. B. (2007). Need for recovery, home-work interference and performance: Is lack of concentration the link? Journal of Vocational Behavior, 71, 204-220.

Eden, D. (2001). Vacations and other respites: Studying stress on and off the job. In C. L. Cooper \& I. T. Robertson (Eds.), International review of industrial and organizational psychology (Vol. 16, pp. 121-146).

Etzion, D., Eden, D., \& Lapidot, Y. (1998). Relief from job stressors and burnout: Reserve service as a respite. Journal of Applied Psychology, 83, 577-585. 
Fredrickson, B. L., Mancuso, R. A., Branigan, C., \& Tugade, M. M. (2000). The undoing effect of positive emotions. Motivation and Emotion, 24, 237-258.

Frese, M., Fay, D., Hilburger, T., Leng, K., \& Tag, A. (1997). The concept of personal initiative: Operationalization, reliability and validity of two German samples. Journal of Occupational and Organizational Psychology, 70, 139-161.

Frese, M., Kring, W., Soose, A., \& Zempel, J. (1996). Personal initiative at work: Differences between East and West Germany. Academy of Management Journal, 39, 37-63.

Fritz, C., \& Sonnentag, S. (2005). Recovery, health and job performance: Effects of weekend experiences. Journal of Occupational Health Psychology, 10, 187-199.

Fritz, C., \& Sonnentag, S. (2006). Recovery, well-being and performance-related outcomes: The role of work load and vacation experiences. Journal of Applied Psychology, 91, 936-945.

Grossman, P., Niemann, L., Schmidt, S., \& Walach, H. (2004). Mindfulness-based stress reduction and health benefits: A meta-analysis. Journal of Psychosomatic Research, 57, 35-43.

Hobfoll, S. E. (1989). Conservation of resources: A new attempt at conceptualizing stress. American Psychologist, 44, 513-524.

Hockey, G. R. J. (1993). Cognitive-energetical control mechanisms in the management of work demands and psychological health. In A. D. Baddeley \& L. Weiskrantz (Eds.), Attention: Selection, awareness, and control: A tribute to Donald Broadbent (pp. 328-345). New York, NY: Clarendon Press/Oxford University Press.

Ilies, R., Scott, B. A., \& Judge, T. A. (2006). The interactive effects of personal traits and experienced states on intraindividual patterns of citizenship behavior. Academy of Management Journal, 49, 561-575.

Jacobsen, E. (1938). Progressive relaxation. Chicago: University of Chicago Press.

Kaplan, D., \& Elliott, P. R. (1997). A didactic example of multilevel structural equation modeling applicable to the study of organizations. Structural Equation Modeling, 4, 1-24.

Luthans, F., Avolio, B. J., Avey, J. B., \& Norman, S. M. (2007). Positive psychological capital: Measurement and relationship with performance and satisfaction. Personnel Psychology, 60, 541-572.

Mathieu, J. E., \& Taylor, S. R. (2006). Clarifying conditions and decision points for mediational type interferences in organizational behavior. Journal of Organizational Bebavior, 27, 1031-1056.

Mehta, P. D., \& Neale, M. C. (2005). People are variables too: Multilevel structural equations modeling. Psychological Methods, 10, 259-284.

Meijman, T. F., \& Mulder, G. (1998). Psychological aspects of workload. In P. J. D. Drenth \& H. Thierry (Eds.), Handbook of work and organizational psychology (2nd ed., Vol. 2, pp. 5-33). Hove: Psychology Press/Erlbaum Taylor and Francis.

Muthén, L. K., \& Muthén, B. (2006). Mplus users guide (version 4). Los Angeles, CA: Author.

Muthén, B., \& Satorra, A. (1995). Complex sample data in structural equation modeling. Sociological Methodology, 25, 216-316.

Parkinson, B., \& Totterdell, P. (1999). Classifying affect-regulation strategies. Cognition and Emotion, 13, 277-303

Pelletier, C. L. (2004). The effect of music on decreasing arousal due to stress: A meta-analysis. Journal of Music Therapy, 41, 192-214.

Podsakoff, P. M., MacKenzie, S. B., Jeong-Yeon, L., \& Podsakoff, N. P. (2003). Common method biases in behavioral research: A critical review of the literature and recommended remedies. Journal of Applied Psychology, 88, 879-903.

Podsakoff, P. M., MacKenzie, S. B., Paine, J. B., \& Bachrach, D. G. (2000). Organizational citizenship behaviors: A critical review of the theroetical and empirical literature and suggestions for future research. Journal of Management, 26, 513-563.

Rasbash, J., Browne, W., Goldstein, H., Yang, M., Plewis, I., Healy, M., et al. (2000). A user's guide to MLwiN. London: Institute of Education, University of London. 
Roe, R. A., Zinovieva, I. L., Dienes, E., \& Horn, L. A. T. (2000). A comparison of work motivation in Bulgaria, Hungary, and The Netherlands: Test of a model. Applied Psychology: An International Review, 49, 658-687.

Rogelberg, S. G., \& Stanton, J. M. (2007). Understanding and dealing with organizational nonresponse. Organizational Research Methods, 10, 195-209.

Ruderman, M. N., Ohlott, P. J., Panzer, K., \& King, S. N. (2002). Benefits of multiple roles for managerial women. Academy of Management Journal, 45, 369-386.

Sarang, P., \& Telles, S. (2006). Effects of two yoga based relaxation techniques on heart rate variability (HRV). International Journal of Stress Management, 13, 460-475.

Sluiter, J. K., van der Beek, A. J., \& Frings-Dresen, M. H. W. (1999). The influence of work characteristics on the need for recovery and experienced health: A study on coach drivers. Ergonomics, 42, 573-583.

Smith, J. C. (2005). Relaxation, meditation, and mindfulness: A mental bealth practitioner's guide to new and traditional approaches. New York, NY: Springer Publishing Co.

Smith, C. A., Organ, D. W., \& Near, J. P. (1983). Organizational citizenship behavior: Its nature and antecedents. Journal of Applied Psychology, 68, 653-663.

Snijders, T. A. B., \& Bosker, R. J. (1999). Multilevel analysis. An introduction to basic and advanced multilevel modeling. London: Sage

Sonnentag, S. (2003). Recovery, work engagement, and proactive behavior: A new look at the interface between nonwork and work. Journal of Applied Psychology, 88, 518-528.

Sonnentag, S., \& Bayer, U.-V. (2005). Switching off mentally: Predictors and consequences of psychological detachment from work during off-job time. Journal of Occupational Health Psychology, 10, 393-414.

Sonnentag, S., Binnewies, C., \& Mojza, E. J. (2008). 'Did you have a nice evening?' A day-level study on recovery experiences, sleep and affect. Journal of Applied Psychology, 93, 674-684.

Sonnentag, S., \& Fritz, C. (2007). The recovery experience questionnaire: Development and validation of a measure for assessing recuperation and unwinding from work. Journal of Occupational Health Psychology, 12, 204-221.

Sonnentag, S., \& Kruel, U. (2006). Psychological detachment from work during off-job time: The role of job stressors, job involvement, and recovery efficacy. European Journal of Work and Organizational Psychology, 15, 197-217

Stewart, G. L., \& Nandkeolyar, A. K. (2006). Adaptation and intraindividual variation in sales outcomes: Exploring the interactive effects of personality and environmental opportunity. Personnel Psychology, 59, 307-332.

Stone, A. A., Kennedy-Moore, E., \& Neale, J. M. (1995). Association between daily coping and end-of-day mood. Health Psychology, 14, 341-349.

Trougakos, J. P., Beal, D. J., Green, S. G., \& Weiss, H. M. (2008). Making the break count: An episodic examination of recovery activities, emotional experiences, and affective delivery. Academy of Management Journal, 51, 131-146.

Van Dyne, L., \& LePine, J. A. (1998). Helping and voice extra-role behaviors: Evidence of construct and predictive validity. Academy of Management Journal, 41, 108-119.

Watson, D., Clark, L. A., \& Tellegen, A. (1988). Development and validation of brief measures of positive and negative affect: The PANAS-scales. Journal of Personality and Social Psychology, 54, 1063-1070

Westman, M., \& Eden, D. (1997). Effects of a respite from work on burnout: Vacation relief and fade-out. Journal of Applied Psychology, 82, 516-527.

Williams, L. J., \& Anderson, S. E. (1991). Job satisfaction and organizational commitment as predictors of organizational citizenship and in-role behaviors. Journal of Management, 17, 601-617.

Received 24 April 2008; revised version received 23 January 2009 